\title{
Optimizing Headspace Temperature and Time Sampling for Identification of Volatile Compounds in Ground Roasted Arabica Coffee
}

\author{
Cristina Sanz, Diana Ansorena, J ose Bello, and Concepción Cid*
}

Departamento de Bromatología, Tecnología de Alimentos y Toxicología, Facultad de Farmacia, Universidad de Navarra, 31080 Pamplona, Spain

\begin{abstract}
Equilibration time and temperature were the factors studied to choose the best conditions for analyzing volatiles in roasted ground Arabica coffee by a static headspace sampling extraction method. Three temperatures of equilibration were studied: 60,80 , and $90^{\circ} \mathrm{C}$. A larger quantity of volatile compounds was extracted at $90^{\circ} \mathrm{C}$ than at 80 or $60^{\circ} \mathrm{C}$, although the same qualitative profile was found for each. The extraction of the volatile compounds was studied at seven different equilibration times: $30,45,60,80,100,120$, and $150 \mathrm{~min}$. The best time of equilibration for headspace analysis of roasted ground Arabica coffee should be selected depending on the chemical class or compound studied. One hundred and twenty-two volatile compounds were identified, including 26 furans, 20 ketones, 20 pyrazines, 9 alcohols, 9 aldehydes, 8 esters, 6 pyrroles, 6 thiophenes, 4 sulfur compounds, 3 benzenic compounds, 2 phenolic compounds, 2 pyridines, 2 thiazoles, 1 oxazole, 1 lactone, 1 alkane, 1 alkene, and 1 acid.
\end{abstract}

Keywords: Static headspace; roasted coffee; volatile compounds

\section{INTRODUCTION}

Due to its unique aroma and flavor, considerable research has been carried out in the analysis of flavorrelated compounds in coffee. Researchers on volatile flavor compounds have used several different techniques (1), all mainly based in the isolation and further identification of the peaks obtained by GC-MS. Other papers include data of sniffing profiles, establishing a relati onship between the presence of certain peaks and their sensorial profiles (2) so that it can be shown that the odor threshold of components was a very important factor from a sensorial point of view.

Headspace sampling is one of the most popular methods for flavor isolation (3) because it is the most suitable for the study of very volatile compounds (4-8) and because its composition better represents the smell that is perceived by the consumer (9).

The direct and accurate analysis of volatiles in ground roasted coffee by static headspace (SH-GC) requires careful standardization of instrumental parameters such as sample size, equilibration time and temperature, and instrumental conditions required for the separation of volatile compounds (10).

Static headspace has been used by different authors when researching volatile flavor compounds; Kallio et al. (11) studied different ratios of several pairs of compounds in the headspace of roasted coffee as an indicator of the storage time of the coffee. Shimoda and Shibamoto (12) used GC-MS with headspace analysis and identified 62 volatile compounds in roasted brewed coffee. Leino et al. (13) characterized the changes in roasted ground Arabica and Robusta coffees stored during 18 months by headspace and identified 38

* Corresponding author (telephone 00-34-948-425600; fax 00-34-948-425659; e--mail ccid@unav.es). volatile compounds. Holscher and Steinhart (14) investigated the volatiles forming the pleasant odor arising from freshly roasted coffee beans by a headspace technique. Bicchi et al. (15) characterized roasted coffee using a static headspace, and Mayer et al. (16) quantified 28 potent odorants extracted with a static headspace from ground coffee samples and brews. A syringe was used to inject the headspace into the chromatograph for analysis in each case. As the injection procedure can be automated using a headspace sampler (17) eliminating the errors associated with manual handling, an HP 7694 static headspace sampler was used for the analysis of the volatile compounds in this work.

There are virtually no reports on the study of the headspace sampling temperature and time for the analysis of vol ati le compounds in ground roasted coffee.

The main objective of our research was to optimize a method based on static headspace gas chromatography (SH-GC) applied to the extraction of volatile compounds from roasted ground Arabica coffee. In addition, a more specific objective was to identify the headspace volatiles obtained by the method and present in every chromatogram. The 122 volatiles identified were grouped by chemical class and semiquantified to find the best equilibration time and temperature for the extraction of the largest quantity of volatile compounds from roasted ground Arabica coffee.

\section{EXPERIMENTAL PROCEDURES}

Materials. A commercial sample (100\% Arabica coffee, roasted) was obtained from a local manufacturer, and just before each analysis, the coffee was ground with a Retsch mill to a particle size of $0.75 \mathrm{~mm}$.

Pure reference standards of 2-methylpropanal, 2-methyl-1propanol, 2-butanone, 3-methylbutanal, 2,3-butanedione, 2,3pentanedione, and 2-butenal were purchased from Acros; 2-propen-1-ol, 3-penten-2-one, 2-pentanol, 2-methylfuran, 


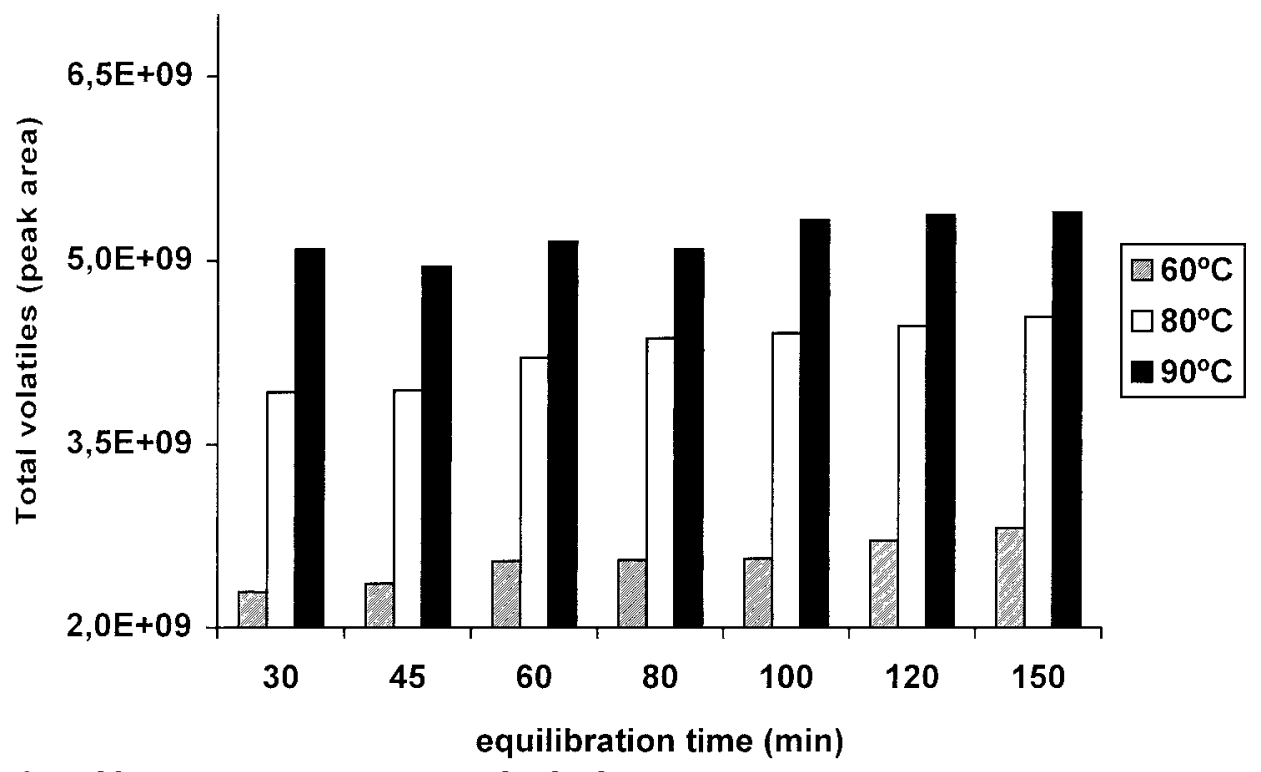

Figure 1. Effect of equilibration temperature on total volatile.

thiophene, propionaldehyde, and dimethyl sulfide were obtained from Aldrich (Steinheim, Germany), and hexanal was obtained from Sigma (Steinheim, Germany).

Static Headspace Gas Chromatography-Mass Spectrometry (SH-GC-MS). SH-GC analysis was performed with an HP 6890 gas chromatograph (Hewlett-Packard) equipped with a static headspace sampler Hewlett-Packard model 7694.

Ten milliliter vials containing $2 \mathrm{~g}$ of roasted ground coffee were immediately sealed with silicone rubber Teflon caps.

Temperature of Equilibration. To choose the optimal temperature of analysis, three different temperatures at seven different equilibration times were tested. Vials were equilibrated at 30, 45, 60, 80, 100, 120, and 150 min using temperatures of 60,80 , and $90{ }^{\circ} \mathrm{C}$.

Time of Equilibration. To select an optimal equilibration time for the extraction of each type of compound, vials were equilibrated at $30,45,60,80,100,120$, and 150 min using a temperature of $90{ }^{\circ} \mathrm{C}$. Analysis was performed in triplicate.

After the vials had been pressurized with carrier gas for 12 $\mathrm{s}, 3 \mathrm{~mL}$ of the coffee headspace sample was injected into a capillary column HP-Wax $(60 \mathrm{~m} \times 0.25 \mathrm{~mm} \times 0.5 \mu \mathrm{m}$ film thickness; Hewlett-Packard).

The injector temperature was set at $180^{\circ} \mathrm{C}$, and helium $(10$ $\mathrm{mL} / \mathrm{min}$ linear speed) was the carrier gas. The oven temperature was maintained at $40{ }^{\circ} \mathrm{C}$ for $6 \mathrm{~min}$ and programmed to $190{ }^{\circ} \mathrm{C}$ at $3{ }^{\circ} \mathrm{C} / \mathrm{min}$.

Mass spectrometry analysis was carried out using a HewlettPackard mass selective detector model 5973 coupled to the gas chromatograph. The mass spectrometer operated in the electron impact ionization mode (70 eV), with a scan range of 33 to $300 \mathrm{amu}$. The ion source temperature was set at $230{ }^{\circ} \mathrm{C}$.

Identification of the Volatile Compounds. Volatile compounds were identified by comparing their spectra to those of the Wiley library and also by comparison of their GC Kovats index and retention time to those of standard compounds and data from literature.

Quantitative Measurements. The total content of the volatile of each headspace analysis was defined by integrating the peak areas of the 122 compounds identified. The relative percentages of individual compounds were calculated from the total contents of volatile on the chromatograms.

Statistical Analysis. The data were subjected to one-way analysis of variance (ANOVA) and a Tukeys posteriori test using SPSS 9.0 for Windows. A significance level of $p \leq 0.05$ was used for all mean evaluations.

\section{RESULTS AND DISCUSSION}

The time and temperature of equilibration are known to be important factors affecting volatile analysis of coffee using SH-GC (10). Volatile analysis by SH-GC was standardized by subjecting $2 \mathrm{~g}$ samples of roasted ground coffee to different equilibration temperatures and time periods.

Effect of Temperature of Equilibration. One way of improving the sensitivity of the headspace technique is by raising the temperature of the sample (17-19) so that more volatile compounds are released from the solid matrix.

The total area of chromatograms obtained at three different equilibration temperatures using seven equilibration times was calculated (Figure 1).

A temperature of $90{ }^{\circ} \mathrm{C}$ permitted the extraction of a larger quantity of volatile compounds than did 80 or 60 ${ }^{\circ} \mathrm{C}$ at each of the seven times of equilibration studied (Figure 1). Figure 2 shows the chromatograms obtained at $60{ }^{\circ} \mathrm{C} / 30 \mathrm{~min}$ and at $90{ }^{\circ} \mathrm{C} / 150 \mathrm{~min}$, and a clear difference in the total area can be observed. However, no differences were found in the qual itative profiles. A temperature of $90{ }^{\circ} \mathrm{C}$ was selected to be used in order to study the influence of the equilibration times on the extraction of the individual volatile compounds in roasted ground coffee.

Effect of Equilibration Time. The factors controlling equilibrium in food systems are very complex, which indicate that Iong equilibration times are needed to reach equilibrium (17). I nitially, the total chromatographic area follows a linear relationship with incubation time, after which it reaches a plateau indicating that equilibrium has been established between the matrix and the headspace.

Table 1 shows the percentage of the extraction of each chemical class at $90^{\circ} \mathrm{C}$ at the seven equilibration times studied. As can be observed in this table, each chemical class had its maximum extraction rate in one of the seven different equilibration times studied: Aldehydes, alcohols, pyrroles, thiophenes, esters, oxazoles, and benzenic compounds are highly extracted at $45 \mathrm{~min}$ of equilibration; ketones, furans, and phenolic compounds at $60 \mathrm{~min}$; lactones at $80 \mathrm{~min}$; and pyridines at $100 \mathrm{~min}$. The quantity of sulfur-containing extracted compounds decreased when the equilibration time was increased, and this was probably due to their sensitivity to $\mathrm{O}_{2}$. The proportion of extracted thiazoles and alkanes did not depend on the time of equilibration programmed, and 


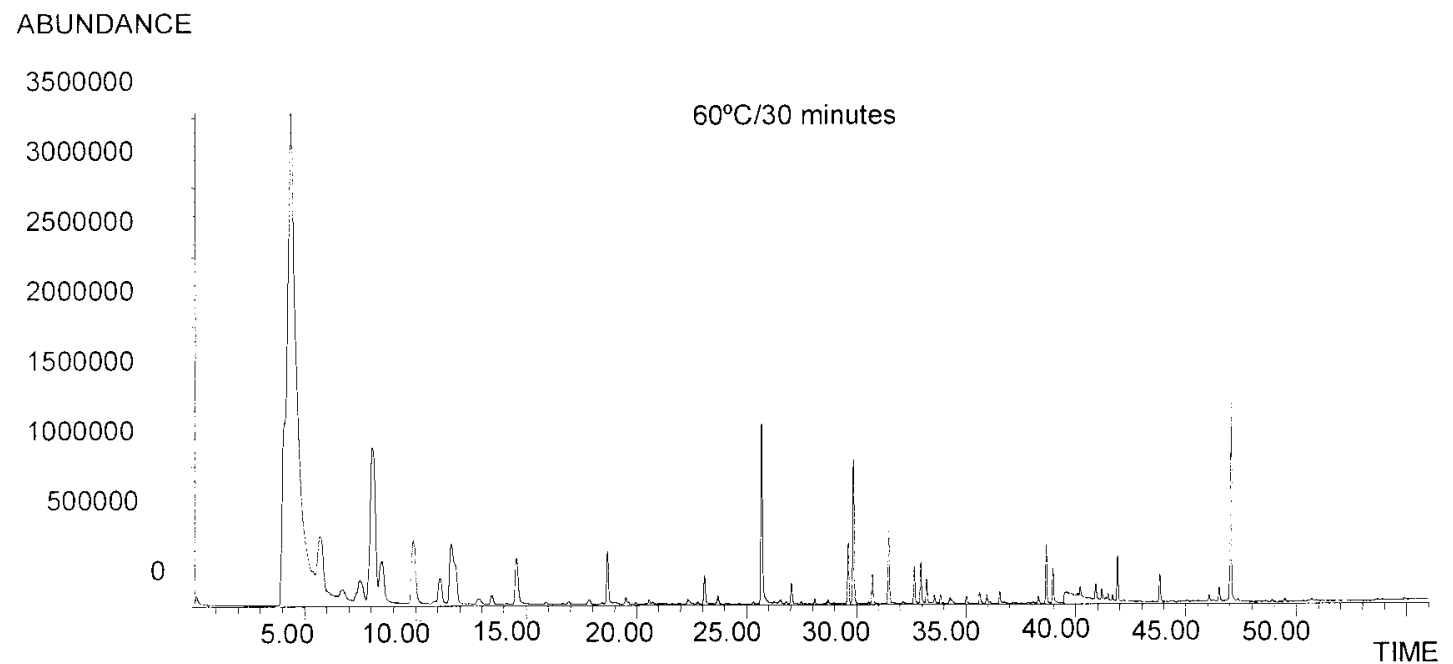

ABUNDANCE

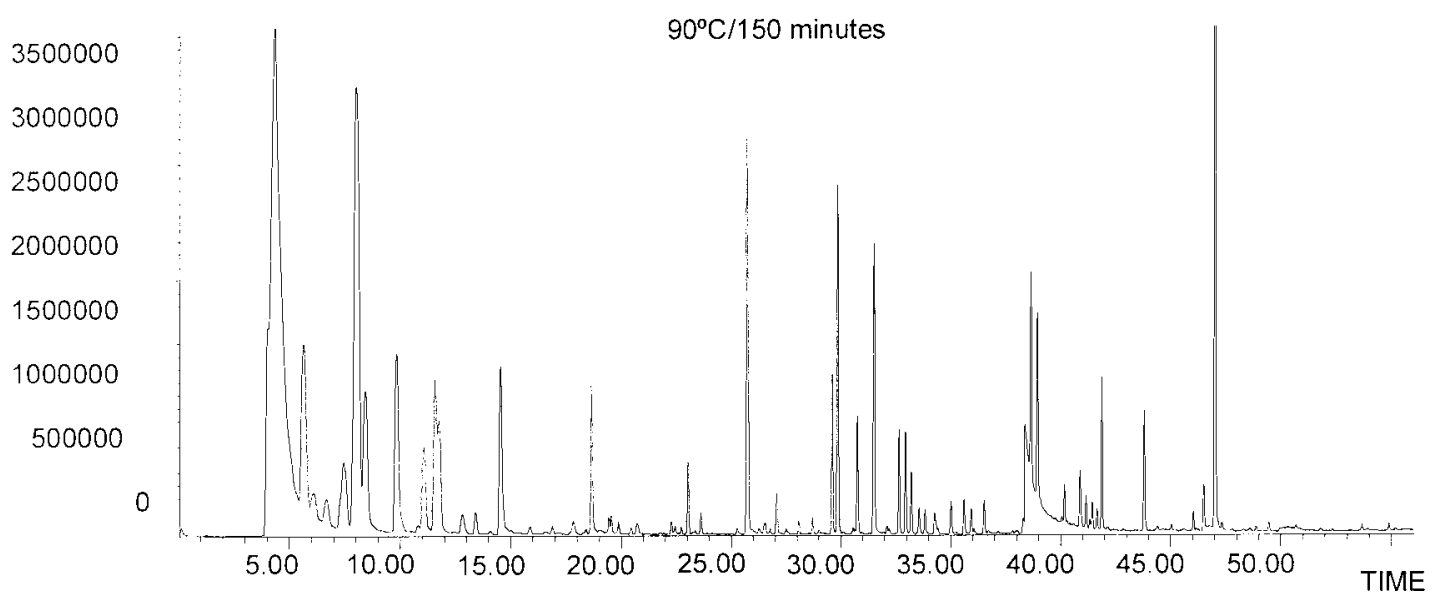

Figure 2. Chromatograms obtained at $60^{\circ} \mathrm{C} / 30 \mathrm{~min}$ and at $90{ }^{\circ} \mathrm{C} / 150 \mathrm{~min}$.

Table 1. Percentages of Extraction of Each Chemical Class with Regard to the Total Area at $90{ }^{\circ} \mathrm{C}$

\begin{tabular}{|c|c|c|c|c|c|c|c|}
\hline compound & $30 \mathrm{~min}$ & $45 \mathrm{~min}$ & $60 \mathrm{~min}$ & $80 \mathrm{~min}$ & $100 \min$ & $120 \mathrm{~min}$ & $150 \mathrm{~min}$ \\
\hline aldehydes & $12.56(2.14)^{a}$ & $13.74(2.48)$ & $13.40(2.84)$ & $12.61(2.16)$ & $12.81(2.23)$ & 13.02 (1.69) & 12.69 (1.40) \\
\hline ketones & $28.40(3.12)$ & $28.45(2.01)$ & $29.24(2.85)$ & $28.04(2.84)$ & $27.50(2.60)$ & $27.40(2.47)$ & 26.79 (2.29) \\
\hline alcohols & $0.94(0.26)$ & $1.02(0.26)$ & $1.01(0.29)$ & $0.94(0.22)$ & $0.95(0.24)$ & $0.95(0.26)$ & $0.97(0.27)$ \\
\hline pyrroles & $1.47(0.30)$ & $1.52(0.21)$ & $1.42(0.27)$ & $1.23(0.37)$ & $1.30(0.27)$ & $1.25(0.17)$ & $1.25(0.14)$ \\
\hline pyrazines & 7.35 (0.49) & 6.05 (1.39) & $6.15(1.46)$ & 7.05 (1.42) & $7.15(0.06)$ & $6.71(0.62)$ & $6.85(0.84)$ \\
\hline furans & $21.31(3.00)$ & 21.37 (1.39) & $21.58(2.48)$ & $20.52(3.23)$ & 21.06 (1.76) & 20.77 (1.57) & 19.97 (1.72) \\
\hline thiazoles & $0.03(0.01)$ & $0.03(0.01)$ & $0.03(0.01)$ & $0.03(0.01)$ & $0.03(0.00)$ & $0.03(0.01)$ & $0.03(0.00)$ \\
\hline thiophenes & $0.20(0.05)$ & $0.23(0.06)$ & $0.20(0.06)$ & $0.18(0.06)$ & $0.19(0.05)$ & $0.19(0.04)$ & $0.19(0.03)$ \\
\hline esters & $3.76(0.42)$ & $4.26(0.04)$ & $4.22(0.16)$ & $4.10(0.14)$ & $4.04(0.12)$ & $4.03(0.04)$ & $3.99(0.07)$ \\
\hline oxazoles & $0.03(0.01)$ & $0.04(0.01)$ & $0.03(0.01)$ & $0.03(0.01)$ & $0.03(0.00)$ & $0.03(0.00)$ & $0.03(0.00)$ \\
\hline lactones & $0.63(0.09)$ & $0.44(0.26)$ & $0.59(0.14)$ & $0.66(0.02)$ & $0.61(0.05)$ & $0.61(0.02)$ & $0.52(0.07)$ \\
\hline sulfur compounds & $0.52(0.13)$ & $0.46(0.11)$ & $0.39(0.07)$ & $0.35(0.09)$ & $0.32(0.07)$ & $0.30(0.04)$ & $0.29(0.05)$ \\
\hline pyridines & $4.06(1.30)$ & 3.04 (1.95) & $3.06(2.25)$ & $3.91(0.23)$ & 4.14 (1.11) & $3.60(0.47)$ & $4.01(0.32)$ \\
\hline alkanes & $0.10(0.01)$ & $0.10(0.01)$ & $0.10(0.01)$ & $0.08(0.02)$ & $0.09(0.02)$ & $0.08(0.01)$ & $0.08(0.01)$ \\
\hline alkenes & $0.43(0.03)$ & $0.44(0.06)$ & $0.45(0.03)$ & $0.45(0.04)$ & $0.45(0.02)$ & $0.45(0.00)$ & $0.44(0.02)$ \\
\hline phenolic compounds & $0.07(0.01)$ & $0.06(0.01)$ & $0.06(0.01)$ & $0.06(0.01)$ & $0.06(0.01)$ & $0.05(0.01)$ & $0.06(0.01)$ \\
\hline acids & $7.31(2.00)$ & 7.56 (3.55) & $7.55(2.51)$ & 8.59 (1.07) & 7.88 (1.58) & 8.75 (1.51) & 8.80 (1.39) \\
\hline benzenic compounds & $0.05(0.01)$ & $0.06(0.01)$ & $0.05(0.01)$ & $0.05(0.02)$ & $0.05(0.01)$ & $0.05(0.01)$ & $0.05(0.01)$ \\
\hline unidentified compounds & 17.16 & 18.29 & 17.28 & 18.78 & 18.44 & 19.57 & 21.00 \\
\hline
\end{tabular}

a Numbers in parentheses are standard deviations.

pyrazines showed an irregular extraction when these times were varied.

No significant differences relating to the total quantity of the volatile compounds extracted were found among the different equilibration times studied.

Volatile Compounds I dentified. One hundred and twenty-two volatile compounds were identified by head- space analysis in roasted ground coffee (Table 2): 26 furans, 20 ketones, 20 pyrazines, 9 alcohols, 9 aldehydes, 8 esters, 6 pyrroles, 6 thiophenes, 4 sulfur compounds, 3 benzenic compounds, 2 phenolic compounds, 2 pyridines, 2 thiazoles, 1 oxazole, 1 lactone, 1 alkane, 1 alkene, and 1 acid. Ninety-nine of them have been previously identified in coffee $(11,13-15,20-25)$. 
Table 2. Volatile Compounds Identified in Headspace Gas of Roasted Ground Coffee

\begin{tabular}{|c|c|c|c|c|c|c|c|c|}
\hline $\mathrm{KI} \mathrm{I}^{\mathrm{a}}$ & $I D^{b}$ & compound $^{c}$ & $\mathrm{~K} \mathrm{I}^{\mathrm{a}}$ & $I D^{b}$ & compound $^{c}$ & $\mathrm{KI} \mathrm{I}^{\mathrm{a}}$ & $I D^{b}$ & compoundc \\
\hline & & aldehydes & & C & $\mathrm{N}$-furfurylpyrrole & 1650 & C & 2-acetyl-5-methylfuran* \\
\hline 645 & $\mathrm{C}$ & acetaldehyde & & & pyrazines & 1686 & C & furfuryl alcohol \\
\hline 712 & A & propanal & 1231 & B & pyrazine & 1706 & C & 5-methyl-2-furfurylfuran* \\
\hline 747 & A & 2-methylpropanal & 1288 & B & 2-methylpyrazine & & & thiazoles \\
\hline 839 & $\mathrm{C}$ & butanal & 1347 & $\mathrm{~B}$ & 2,5-dimethylpyrazine & 1260 & C & 2-methylthiazole \\
\hline 880 & C & 2-methylbutanal & 1353 & B & 2,6-dimethylpyrazine & 1270 & C & 1,3-thiazole \\
\hline 884 & A & 3-methyl butanal & 1359 & B & 2-ethylpyrazine & & & thiophenes \\
\hline 1042 & A & 2-butenal & 1372 & C & 2,3-dimethyl pyrazine & 1021 & A & thiophene \\
\hline 1084 & A & hexanal & 1411 & C & 2-ethyl-6-methylpyrazine & 1097 & B & 2-methylthiophene \\
\hline \multirow[t]{2}{*}{1102} & $\mathrm{C}$ & 2-methyl-2-butenal & 1419 & C & 2-ethyl-5-methylpyrazine & 1127 & $\mathrm{C}$ & 3-methylthiophene \\
\hline & & ketones & 1432 & $\mathrm{C}$ & 2-ethyl-3-methylpyrazine & 1185 & C & 2-ethylthiophene* \\
\hline 753 & C & 2-propanone* & 1433 & C & 2,3,5-trimethylpyrazine & 1565 & $\mathrm{C}$ & 2-methyltetrahydrothiophen-3-one* \\
\hline 866 & A & 2-butanone & 1447 & $\mathrm{C}$ & N-propylpyrazine* & 1734 & $\mathrm{C}$ & 2-thiophencarboxal dehyde \\
\hline 962 & A & 2,3-butanedione & 1463 & C & 2,6-diethylpyrazine & & & esters \\
\hline 1053 & C & 3-hexanone & 1467 & C & 2-vinylpyrazine* & 782 & C & acetic acid, methyl ester \\
\hline 1058 & A & 2,3-pentanedione & 1474 & $\mathrm{C}$ & 3-ethyl-2,5-dimethylpyrazine* & 850 & B & acetic acid, ethyl ester \\
\hline 1138 & A & 3-penten-2-one & 1493 & C & 2,3-dimethyl-5-ethylpyrazine & 872 & $\mathrm{C}$ & propanoic acid, methyl ester \\
\hline 1143 & C & 3,4-hexanedione & 1521 & $\mathrm{C}$ & 2-methyl-6-vinylpyrazine* & 1015 & $\mathrm{C}$ & isovaleric acid, methyl ester \\
\hline 1307 & $\mathrm{C}$ & 3-hydroxy-2-butanone & 1524 & $\mathrm{C}$ & 2-methyl-3,5-diethylpyrazine & 1050 & $\mathrm{C}$ & methyl thiol acetate* \\
\hline 1323 & $\mathrm{C}$ & 1-hydroxy-2-propanone & 1529 & C & 2-methyl-5-vinylpyirazine & 1266 & $\mathrm{C}$ & 3-methyl-2-buten-1-ol, acetate* \\
\hline 1366 & $\mathrm{C}$ & 2-hydroxy-3-pentanone & 1665 & $\mathrm{C}$ & 2-acetylpyrazine & 1335 & $\mathrm{C}$ & lactic acid, methyl ester* \\
\hline 1385 & C & 2-cyclopenten-1-one & 1667 & C & 5-methyl-6,7-dihydro-(5H)- & 1403 & C & glycolic acid, methyl ester* \\
\hline 1397 & $\mathrm{C}$ & 2-methyl-2-cyclopenten-1-one & & & ovlonentanyrazine & & & oxazoles \\
\hline 1351 & $\mathrm{C}$ & 1-hydroxy-2-butanone & & & furans & 1214 & $\mathrm{C}$ & trimethyloxazole \\
\hline 1483 & C & 1-acetyloxy-2-propanone & 716 & C & furan & & & lactones \\
\hline 1546 & $\mathrm{C}$ & 1-(2-furyl)-2-propanone* & 832 & $\mathrm{C}$ & 3-methylfuran & 1673 & $\mathrm{C}$ & $\gamma$-butyrolactone* \\
\hline 1549 & C & 3,3-dimethyl-2-butanone & 858 & A & 2-methylfuran & & & sulfur compounds \\
\hline 1554 & $\mathrm{C}$ & 1-acetyloxy-2-butanone & 930 & B & 2,5-dimethylfuran & 635 & C & methanethiol \\
\hline 1562 & $\mathrm{C}$ & 3-methyl-2-cyclopenten-1-one & 975 & B & 2-ethylfuran & 660 & $\mathrm{C}$ & carbon disulfide \\
\hline 1582 & C & 2,3-dimethylcyclopent-2-en-1-one & 1056 & B & 2,3,5,-trimethylfuran & 671 & A & dimethyl sulfide \\
\hline 1723 & $\mathrm{C}$ & $\begin{array}{l}\text { 1-(5-methyl-2-pyrazinyl)-1-ethanone* } \\
\text { alcohols }\end{array}$ & $\begin{array}{l}1160 \\
1181\end{array}$ & B & $\begin{array}{l}\text { 2-vinyl-5-methylfuran } \\
\text { 2-(2-propenyl)-furan* }\end{array}$ & 1077 & $\mathrm{~B}$ & $\begin{array}{l}\text { dimethyl disulfide } \\
\text { pyridines }\end{array}$ \\
\hline 913 & C & ethanol & 1220 & $\mathrm{C}$ & 2-propenylfuran & 1203 & B & pyridine \\
\hline 1026 & C & 2-butanol* & 1241 & C & 2-pentylfuran & 1239 & $\mathrm{C}$ & 2-methylpyridine \\
\hline 1103 & A & 2-methyl-1-propanol & 1251 & B & 2-(methoxymethyl)furan & & & alkanes \\
\hline 1124 & A & 2-propenol* & 1283 & B & 2-methyltetrahydrofuran-3-one & 915 & C & 2,2,4,6,6-pentamethylheptane* \\
\hline 1130 & A & 2-pentanol* & 1304 & $\mathrm{C}$ & trans-2-methyl-5n-propenylfuran* & & & alkenes \\
\hline 1220 & C & 3-methylbutan-1-ol & 1462 & C & 5-methyl-3-tetrahydrofuran-2-one & 624 & C & 1,3-pentadiene \\
\hline 1264 & $\mathrm{C}$ & 3-methyl-3-buten-1-ol & 1490 & $\mathrm{C}$ & 2-furancarboxal dehyde & & & phenolic compounds \\
\hline 1332 & $\mathrm{C}$ & 2-heptanol & 1516 & C & 2-furfuryl methyl sulfide & 1075 & C & phenol \\
\hline 1337 & $\mathrm{C}$ & $\begin{array}{l}\text { 3-methyl-2-buten-1-ol } \\
\text { pyrroles }\end{array}$ & $\begin{array}{l}1536 \\
1519\end{array}$ & $\begin{array}{l}\mathrm{C} \\
\mathrm{C}\end{array}$ & $\begin{array}{l}\text { 2-acetylfuran } \\
\text { furfuryl formate }\end{array}$ & & C & $\begin{array}{l}\text { 2-methoxyphenol } \\
\text { benzenic compounds }\end{array}$ \\
\hline 1149 & B & 1-methylpyrrole & 1559 & C & furfuryl acetate & 1040 & $B$ & toluene \\
\hline 1194 & $\mathrm{C}$ & 1-ethyl-1H-pyrrole & 1605 & C & 5-methylfurfural & 1273 & $\mathrm{C}$ & ethenylbenzene \\
\hline 1542 & $\mathrm{C}$ & 1H-pyrrole & 1620 & $\mathrm{C}$ & furfuryl propionate & 1248 & $\mathrm{C}$ & p-methylanisole* \\
\hline 1661 & C & 2-formyl-1-methylpyrrole & 1626 & C & 2,2'-bis(furan) & & & acids \\
\hline 1647 & C & 2-acetyl-1-methyl pyrrole & 1636 & $\mathrm{C}$ & 2-furfurylfuran & 1480 & B & acetic acid \\
\hline
\end{tabular}

${ }^{a} \mathrm{KI}$, Kovats index calculated for the HP-Wax capillary column. ${ }^{\mathrm{b}}$ The reliability of the identification proposal is indicated by the following: $A$, mass spectrum, retention time, and Kovats index agreed with standards; $B$, mass spectrum and Kovats index agreed with literature data; C, mass spectrum, compared with Wiley mass spectral databases. ${ }^{C}$ Asterisks denote compounds not previously identified in other papers. Note: Work conditions: $90{ }^{\circ} \mathrm{C}$ and all equilibrium times tested.

However, the smell of coffee is not necessarily connected with the number of peaks in the chromatogram. The odor threshold is much more important than any detector response, and it should be studied with other techniques such as sniffing.

Large amounts of ketones, furans, and aldehydes were detected in roasted ground coffee. Among the ketones, 2-propanone, 2,3-butanedione, and 1-hydroxy2-propanone were particularly high. Of all the compounds extracted, at $90{ }^{\circ} \mathrm{C}$, 2-propanone represented between $15.50 \%$ at $45 \mathrm{~min}$ and $14.50 \%$ at $150 \mathrm{~min}$. 2,3Butanedione, responsible for the buttery note in roasted ground coffee $(14,25-27)$, constituted between 3.09\% at $60 \mathrm{~min}$ and $2.48 \%$ at $100 \mathrm{~min}$ and 1-hydroxy-2propanone between $1.92 \%$ at $30 \mathrm{~min}$ and $1.29 \%$ at 45 min (Table 3). These low molecular weight ketones are quite abundant in coffee and readily lost during storage (28).

The furans are particularly important in quantity and quality of coffee flavor (29) with 99 members identified. Holscher and Steinhart (14) identified 23 furans that were the major constituents of the headspace sample
(13.8\%). Twenty-six furans were identified in this work representing, at $90{ }^{\circ} \mathrm{C}$, between $21.58 \%$ of all the compounds extracted at $60 \mathrm{~min}$ and $19.97 \%$ at $150 \mathrm{~min}$ (Table 1).

Numerous furan compounds in coffee are often re sponsible for the burnt sugar, burnt, and caramel aromas $(1,13)$. Furfuryl alcohol, which appears to be the compound with the lowest vapor pressure in a headspace over brewed coffee (12), has been associated with bitter and burnt aromas $(13,28)$. However, Ho et al. (29) related that alkyl- and alkenyl-substituted furans, such as 3-methylfuran, do not present any sensory interest. Furfuryl alcohol and 3-methylfuran were the most abundant furans identified in our work representing, at $90{ }^{\circ} \mathrm{C}$, between $7.89 \%$ of all the volatiles extracted at $30 \mathrm{~min}$ and $6.86 \%$ at $150 \mathrm{~min}$ for furfuryl alcohol and between $6.29 \%$ at $45 \mathrm{~min}$ and $5.47 \%$ at 80 min for 3-methylfuran (Table 3).

Among the aldehydes, which are considered to be some of the most volatile components in coffee (28), acetaldehyde, propanal, and 2-methylpropanal were predominantly present and were related by Semmel roch 
Table 3. Percentages of Extraction of Some Volatile Compounds with Regard to the Total Area at $90{ }^{\circ} \mathrm{C}$

\begin{tabular}{|c|c|c|c|c|c|c|c|}
\hline compound & $30 \mathrm{~min}$ & $45 \mathrm{~min}$ & $60 \mathrm{~min}$ & $80 \mathrm{~min}$ & $100 \mathrm{~min}$ & $120 \mathrm{~min}$ & $150 \mathrm{~min}$ \\
\hline 2-propanone & $14.74(1.53)$ & $15.50(1.56)$ & $15.43(1.57)$ & $15.37(1.41)$ & $14.80(1.23)$ & $14.70(1.48)$ & $14.50(1.00)$ \\
\hline 2,3-butanedione & $2.92(0.30)$ & $2.86(0.33)$ & $3.09(0.39)$ & $2.77(0.10)$ & $2.48(0.27)$ & $2.66(0.08)$ & $2.55(0.31)$ \\
\hline 1-hydroxy-2-propanone & $1.92(0.32)$ & $1.29(0.56)$ & $1.80(0.08)$ & $1.78(0.34)$ & $1.81(0.26)$ & $1.75(0.24)$ & $1.59(0.34)$ \\
\hline furfuryl alcohol & $7.89(2.02)$ & $7.05(0.78)$ & $7.71(0.87)$ & $7.87(1.42)$ & $7.84(0.65)$ & $7.54(0.65)$ & 6.86 (1.05) \\
\hline 3-methylfuran & $5.61(0.76)$ & $6.29(1.00)$ & $5.90(1.23)$ & $5.47(1.01)$ & $5.69(0.98)$ & $5.90(0.36)$ & $5.46(0.46)$ \\
\hline acetal dehyde & $2.04(0.31)$ & $2.13(0.32)$ & $2.15(0.26)$ & $2.11(0.34)$ & $2.04(0.29)$ & $2.00(0.31)$ & $1.95(0.24)$ \\
\hline 2-methylpropanal & $4.03(0.69)$ & $4.36(0.86)$ & $4.32(0.91)$ & $4.18(0.64)$ & 4.20 & 4.25 & $0.49)$ \\
\hline propanal & $2.30(0.26)$ & $2.40(0.26)$ & $2.49(0.25)$ & $2.44(0.29)$ & $2.40(0.29)$ & $2.35(0.28)$ & $2.31(0.19)$ \\
\hline ethanol & $0.64(0.26)$ & $0.61(0.18)$ & $0.71(0.29)$ & $0.66(0.25)$ & $0.66(0.26)$ & $0.65(0.26)$ & $0.67(0.28)$ \\
\hline 1-methylpyrrole & $0.73(0.21)$ & $0.78(0.17)$ & $0.73(0.22)$ & $0.63(0.24)$ & $0.67(0.22)$ & $0.67(0.12)$ & $0.66(0.12)$ \\
\hline 2-methylpyrazine & $3.63(0.30)$ & $3.74(0.55)$ & $2.98(0.66)$ & $3.61(0.84)$ & $3.58(0.13)$ & $3.46(0.46)$ & $3.46(0.58)$ \\
\hline 2-methoxyphenol & $0.07(0.01)$ & $0.06(0.01)$ & $0.06(0.01)$ & $0.05(0.01)$ & $0.06(0.01)$ & $0.05(0.01)$ & $0.05(0.01)$ \\
\hline
\end{tabular}

a Numbers in parentheses are standard deviations.

and Grosch $(25,27)$ to be potent odorants of coffee powders and brews. Acetal dehyde constituted between $2.15 \%$ of all the extracted compounds at $60 \mathrm{~min}$ and $1.95 \%$ at $150 \mathrm{~min}, 2$-methylpropanal between $4.36 \%$ at $45 \mathrm{~min}$ and $4.03 \%$ at $30 \mathrm{~min}$, and propanal between $2.49 \%$ at $60 \mathrm{~min}$ and $2.30 \%$ at $30 \mathrm{~min}$ (Table 3 ).

Alcohols were present at relatively high concentrations in freshly roasted coffee, although they are readily lost by volatilization and oxidation. Ethanol was the most abundant alcohol detected in the ground roasted coffee studied, but it represented only between $0.71 \%$ at $60 \mathrm{~min}$ at $90{ }^{\circ} \mathrm{C}$ and $0.64 \%$ at $30 \mathrm{~min}$ (Table 3).

Four sulfur-containing compounds such as methanethiol, dimethyl sulfide, dimethyl disulfide, and carbon disulfide were detected in roasted ground coffee using headspace gas analysis. Sulfur compounds, which are known to be very $\mathrm{O}_{2}$ sensitive (14), have very low threshold values and play an important role in the aroma (26). The most important one is methanethiol, which mainly corresponds to the decrease of aroma freshness (14). Due to the $\mathrm{O}_{2}$ sensitivity of the sulfurcontaining compounds, the quantity of this chemical class extracted decreased when the time of equilibration increased, from $0.52 \%$ at $30 \mathrm{~min}$ to $0.29 \%$ at $150 \mathrm{~min}$ (Table 1). All four of the sulfur-containing compounds were highly extracted when using $30 \mathrm{~min}$ as the equilibration time.

Leino et al. (13) reported that 1-methylpyrrole was the only volatile al kylpyrrole detected with the headspace technique. In this work, five other pyrroles were identified: 1-ethyl-1H-pyrrole, 1H-pyrrole, 2-formyl-1methyl pyrrole, 2-acetyl-1-methylpyrrole, and $\mathrm{N}$-furfurylpyrrole. 1-Methylpyrrole was the most abundant pyrrole, representing between $0.78 \%$ at $45 \mathrm{~min}$ and $0.63 \%$ at $80 \mathrm{~min}$ (Table 3 ).

Flament (30) found 79 pyrazines in coffee, and Clarke (28) reported that 81 compounds containing a pyrazine ring have been detected. Twenty pyrazines have been detected by headspace gas analysis in this work. 2-Methyl pyrazine was the most abundant one detected in our coffee, representing, at $90{ }^{\circ} \mathrm{C}$, between $2.98 \%$ at $60 \mathrm{~min}$ and $3.74 \%$ at $45 \mathrm{~min}$ of all the compounds extracted (Table 3).

Pyrazines are abundant in coffee (13) and are usually associated with the generation of roasted and burnt flavor notes (29), although it may alter depending on the concentration and by synergistic/antagonistic effects among the compounds present (13). Many pyrazines are recognized as the volatiles contributing to roasted aromas of cooked foods $(12,21)$.

Two pyridines have been detected in roasted ground coffee: pyridine and 2-methylpyridine. Pyridine has bitter and roasty notes, and 2-methylpyridine is astringent $(26,28)$. Pyridines have been found in only a relatively small number of foods that have been subjected to some heat treatment (31). The presence of pyridines is often associated with off-flavors. Pyridines are described as having green, bitter, astringent, and/ or roasty notes.

One phenolic compound was detected in roasted ground coffee. This type of compound, usually present in coffee in low concentrations, has been related to burnt aroma and other aromas such as smoky, spicy, or clove like and also imparts astringency $(26,28)$. 2-Methoxyphenol is the unique phenolic compound detected in our work between $0.05 \%$ at 80,120 , and $150 \mathrm{~min}$ and $0.07 \%$ at $30 \mathrm{~min}$ (Table 3).

Trace amounts of thiazoles, thiophenes, esters, oxazoles, lactones, al kanes, alkenes, benzenic compounds, and acids were also detected in roasted ground coffee.

In summary, at higher temperature of equilibration, greater extraction of the volatile compounds was obtained and no differences in the qualitative profiles were observed. When the time of equilibration was increased, the quantity of the volatile compounds extracted also increased, but in an irregular way depending on the chemical family considered. The time of equilibration for headspace analysis of roasted ground Arabica coffee should be selected depending on the chemical class or the compound that is being studied: short equilibration times for the analysis of sulfur compounds, aldehydes, alcohols, pyrroles, pyrazines, thiophenes, esters, and phenolic compounds and longer times for pyridines, ketones, acids, and furans.

\section{LITERATURE CITED}

(1) Lee, T. A.; Kempthorne, R.; Hardy, J . H. Compositional changes in brewed coffee as a function of brewing time. J . Food Sci. 1992, 57 (6), 1417-1419.

(2) Grosch, W. Detection of potent odorants in foods by aroma extract dilution analysis. Trends F ood Sci. Technol. 1993, 4, 68-73.

(3) Zhou, M.; Robards, K.; Glennie-Holmes, M.; Helliwell, $\mathrm{S}$. Analysis of Volatile Compounds and Their Contribution to Flavor in Cereals. J. Agric. Food Chem. 1999, 47, 3241-3953.

(4) Tassan, C. G.; Russel I, G. F. Sensory and gas chromatographic profiles of coffee beverage headspace volatiles entrained on porous polymers. J. Food Sci. 1974, 39, 64.

(5) Medina, I.; Suarez, J. J .; Martinez, J. L. Aromas alimentarios I. Aliment., Equip. Tecnol. 1994, 6, 8792.

(6) Yang, X.; Peppard, T. Solid-phase microextraction for flavor analysis. J. Agric. Food Chem. 1994, 42, 19251930. 
(7) Falqué, E.; Darriet, P.; Fernández, E.; Dubourdieu, D. Compuestos aromáticos de un vino por acoplamiento C.G.-E.M. "Sniffing". Alimentaria 1995, J uly/Aug, 8184.

(8) Barcarolo, R.; Tutta, C.; Casson, P. Aroma Compounds. In Handbook of F ood Analysis; Nollet, L., Ed.; Dekker: New York, 1996.

(9) Pollien, P.; Ott, A.; Montigon, F.; Baumgartner, M.; Muñoz-B ox, R.; Chaintreau, A. Hyphenated HeadspaceGas Chromatography-Sniffing Technique: Screening of I mpact Odorants and Quantitative Aromagram Comparisons. J . Agric. Food Chem. 1997, 45, 2630-2637.

(10) Medina, I.; Satue-Gracia, M. T.; Frankel, E. N. Static Headspace gas chromatographic analyses to determine oxidation of fish muscle lipids during thermal processing. J . Am. Oil Chem. Soc. 1999, 76 (2), 231-236.

(11) Kallio, H.; Leino, M.; Koullias, K.; Kallio, S.; Kaitaranta, $\mathrm{J}$. Headspace of roasted ground coffee as an indicator of storage time. Food Chem. 1990, 36, 135-148.

(12) Shimoda, M.; Shibamoto, T. I solation and identification of headspace volatiles from brewed coffee with an oncolumn GC-MS method. J . Agric. Food Chem. 1990, 38, 802-804.

(13) Leino, M.; Lapveteläinen, A.; Menchero, P., Malm, H.; Kaitaranta, J .; Kallio, H. Characterization of stored Arabica and Robusta coffees by headspace-GC and sensory analysis. Food Qual. Pref. 1991/2, 3, 115-125.

(14) Holscher, W.; Steinhart, H. Investigation of roasted coffee freshness with an improved headspace technique. Z. Lebensm. Unters. Forsch. 1992, 195, 33-38.

(15) Bicchi, C. P.; Binello, A. E.; Legovich, M. M.; Pellegrino, G. M.; Vanni, A. C. Characterization of Roasted Coffee by S-HSGC and HPLC-UV and Principal Component Analysis. J . Agric. Food Chem. 1993, 41, 2324-2328.

(16) Mayer, F.; Czerny, M.; Grosch, W. Influence of provenance and roast degree on the composition of potent odorants in Arabica coffees. Eur. Food Res. Technol. 1999, 209, 242-250.

(17) Girard, B.; Nakai, S. Static headspace gas chromatographic method for volatiles in canned salmon. J . Food Sci. 1991, 56 (5), 1271-1274.

(18) Ahn, D. U.; J O, C.; Olson, D. G. Volatile profiles of raw and cooked turkey thigh as affected by purge temperature and holding time before purge. J . Food Sci. 1999, 64, 230-233.
(19) Operating and Service Manual. Headspace Sampler HP 7694E, Hewlett-Packard.

(20) Harada, K.; Nishimura, O.; Mihara, S. Rapid analysis of coffee flavour by gas chromatography using a pyrolyzer. J . Chromatogr. 1987, 391, 457-460.

(21) Maarse, H.; Visscher, C. A. Volatile Compounds In Foods; TNO-CIVO Food Analysis Institute: Zeist, The Netherlands, 1989.

(22) Spadone, J. C.; Liardon, R. Analytical study of the evolution of coffee aroma compounds during storage. ASIC, 13th Colloque, Paipa; ASIC: Paris, France, 1989.

(23) Leino, M.; Kaitaranta, J .; Kallio, H. Comparison of changes in Headspace volatiles of some Coffee Blends during storage. Food Chem. 1992, 43, 35-40.

(24) Murota, A. Canonical discriminant analysis applied to the headspace GC profiles of coffee cultivars. Biosci., Biotechnol., Biochem. 1993, 57 (7), 1043-1048.

(25) Semmelroch, P.; Grosch, W. Analysis of roasted coffee powders and brews by gas chromatography-ol factometry of headspace samples. Lebensm.- Wiss. -Technol. 1995, 28, 310-313.

(26) Illy, A.; Viani, R. Espresso Coffee: The Chemistry of Quality; Illy, A., Viani, R., Eds.; Academic Press; London, U.K., 1995.

(27) Semmelroch, P.; Grosch, W. Studies on character impact odorants of coffee brews. J . Agric. Food Chem. 1996, 44 537-543.

(28) Clarke, R. J .; Macrae, R. Coffee. In Chemistry; Clarke, R. J., Macrae, R., Eds.; Elsevier Science Publishers: Barking, Essex, U.K., 1985; Vol. 1.

(29) Ho, C.-T.; Hwang, H.-I.; Yu, T.-H.; Zhang, J . An overview of the Maillard reactions related to aroma generation in coffee. ASIC, 15th Colloque, Montpellier; ASIC: Paris, France, 1993.

(30) Flament, I. Volatile compounds. In Foods and Beverages; Maarse, H., Ed.; Dekker: New York, 1991.

(31) Maga, J . A. Pyridines in Foods. J . Agric. Food Chem. 1981, 29, 895-898.

Received for review September 6, 2000. Revised manuscript received December 29, 2000. Accepted December 29, 2000. We thank PIUNA (Plan Investigacion Universidad de Navarra) for supporting the development of this work.

J F 001100R 